\title{
A Correlation Analysis of the Relationship between Land Use and Land Cover/Land Surface Temperature in Abuja Municipal, FCT, Nigeria
}

\author{
M. E. Awuh ${ }^{1}$, P. O. Japhets ${ }^{1}$, M. C. Officha' ${ }^{2}$, A. O. Okolie ${ }^{3}$, I. C. Enete ${ }^{1}$ \\ ${ }^{1}$ Department of Geography \& Meteorology, NAU, Awka, Nigeria \\ ${ }^{2}$ Department of Architecture, NAU, Awka, Nigeria \\ ${ }^{3}$ Department of Architecture, Chukwuemeka Odumegwu Ojukwu University, Uli, Nigeria \\ Email: *awuhekolok@yahoo.co.uk
}

How to cite this paper: Awuh, M.E., Japhets, P.O., Officha, M.C., Okolie, A.O. and Enete, I.C. (2019) A Correlation Analysis of the Relationship between Land Use and Land Cover/Land Surface Temperature in Abuja Municipal, FCT, Nigeria. Journal of Geographic Information System, 11, 44-55. https://doi.org/10.4236/jgis.2019.111004

Received: November 22, 2018

Accepted: February 10, 2019

Published: February 13, 2019

Copyright $\odot 2019$ by author(s) and Scientific Research Publishing Inc. This work is licensed under the Creative Commons Attribution International License (CC BY 4.0).

http://creativecommons.org/licenses/by/4.0/

\begin{abstract}
This study adopted Remote Sensing and GIS in assessing Land Use and Land Cover (LULC)/Land Surface Temperature (LST) variation in Abuja Municipal, FCT from 1986 to 2016 . The thirty-year study period was chosen with the specific objective to determine the relationship between LULC and LST using a correlation analysis. Three Landsat TM/ETM+ images of the study area (1986, 2001 and 2016) were used to carry out the study. LULC was found to increase by $246.96 \mathrm{~km}^{2}$ (86.4\%) in areal extent of built-up between 1986 and 2016; the spatial extent of the LST was found to increase on average from $23.5^{\circ} \mathrm{C}$ to $30.2^{\circ} \mathrm{C}$. The correlation analysis showed a strong coefficient of determination $\left(r^{2}\right)$. The correlation analyses proved that the LULC classes were strongly related to LST. A strong correlation between the LULC classes and LST was observed at $0.8266,0.9486$, and 0.77 for 1986, 2001, and 2016. The coefficient of determination $\left(r^{2}\right)$ for 2016 was 0.77 , being a strong indicator that a strong relationship existed implying that built-up areas were major drivers of the variation in the LST in Abuja Municipal. To promote thermal comfort in Abuja Municipal, urban planning, and control of building patterns tree-planting exercises are some of the recommendations made.
\end{abstract}

\section{Keywords}

Correlation Analysis, Remote Sensing, Abuja, LULC/LST Relationship

\section{Introduction}

Urbanization causes major issues, one of which is the alteration of land surface 
conditions that lead to a modified thermal climate which makes the cities warmer than surrounding rural areas [1]. Changes in Land Use/Land Cover (LULC) alter the local climate of an area [2] [3], in terms of its radiative, aerodynamic and energy balance [4]. Studies such as [2] [5] attested that landscape dynamics involving urbanization and associated LULC changes had contributed to the increase in land surface temperature which resulted in the relative warming of the urban areas in comparison to areas where natural land cover and vegetation still existed.

Several authorities have acknowledged that the integration of remotely sensed LST/LULC and statistical tools can provide spatially continuous data over a whole city or region, permitting visualization of spatial relationships between temperature patterns and urban land uses including infrastructural features [6] [7] [8] [9] [10]. These studies are useful in showing the relationship between LULC and LST variation in many cities across the world [8] [9] [11].

Abuja, the study area, has witnessed a large influx of people into the city; this unprecedented increase has led to the emergence of satellite towns and smaller settlements to accommodate this increased populace [12]. Considering the fact that urbanisation is usually associated with landscape dynamics, this study assesses the interconnectedness between the changing Landscape and LST in Abuja.

\section{Material and Method}

\subsection{Study Area}

The study area, Abuja Municipal Area Council, is located between latitudes $8^{\circ} 37^{\prime} 41^{\prime \prime}$ and $9^{\circ} 9^{\prime} 15^{\prime \prime}$ north of the equator, and longitudes $7^{\circ} 3^{\prime} 55^{\prime \prime}$ and $7^{\circ} 34^{\prime}$ east of the Greenwich Meridian. It is bound to the north by Bwari Local Government Area (LGA), to the east by Karu LGA, to the south by Kuje LGA, to the west by Gwagwalada LGA, and southwest by Nasarawa LGA in Nasarawa State. This region has an area of approximately $1456 \mathrm{~km}^{2}$. It is regarded as the Capital City and is the centre of most commercial and governmental agencies. The area contains the following districts and satellite towns; Central Business District, Maitama, Asokoro, Wuse, Kubwa, Lugbe etc. as depicted in Figure 1.

The metropolitan area of Abuja has a projected population of 3,564,126 persons, making it the fourth largest metropolitan area in Nigeria, behind Lagos, Kano and Ibadan [13]. Abuja, under Koppen climate classification (Aw), has a tropical wet and dry climate. The FCT experiences three weather conditions annually. This includes a warm, humid rainy season and a scorching dry season. In between the two, there is a brief interlude of harmattan (northeast trade wind) with the main feature of dust haze, intensified coldness and dryness. In Abuja, the rainy season begins from April and ends in October with September being the peak. Due to the hilly and mountainous nature of Abuja city, orographic activities bring heavy and frequent rainfall of about $1500 \mathrm{mms}$ (59.1 in) during the rainy season. Annual rainfall is the highest within the FCC, about $1631.7 \mathrm{~m}$ [14]. 


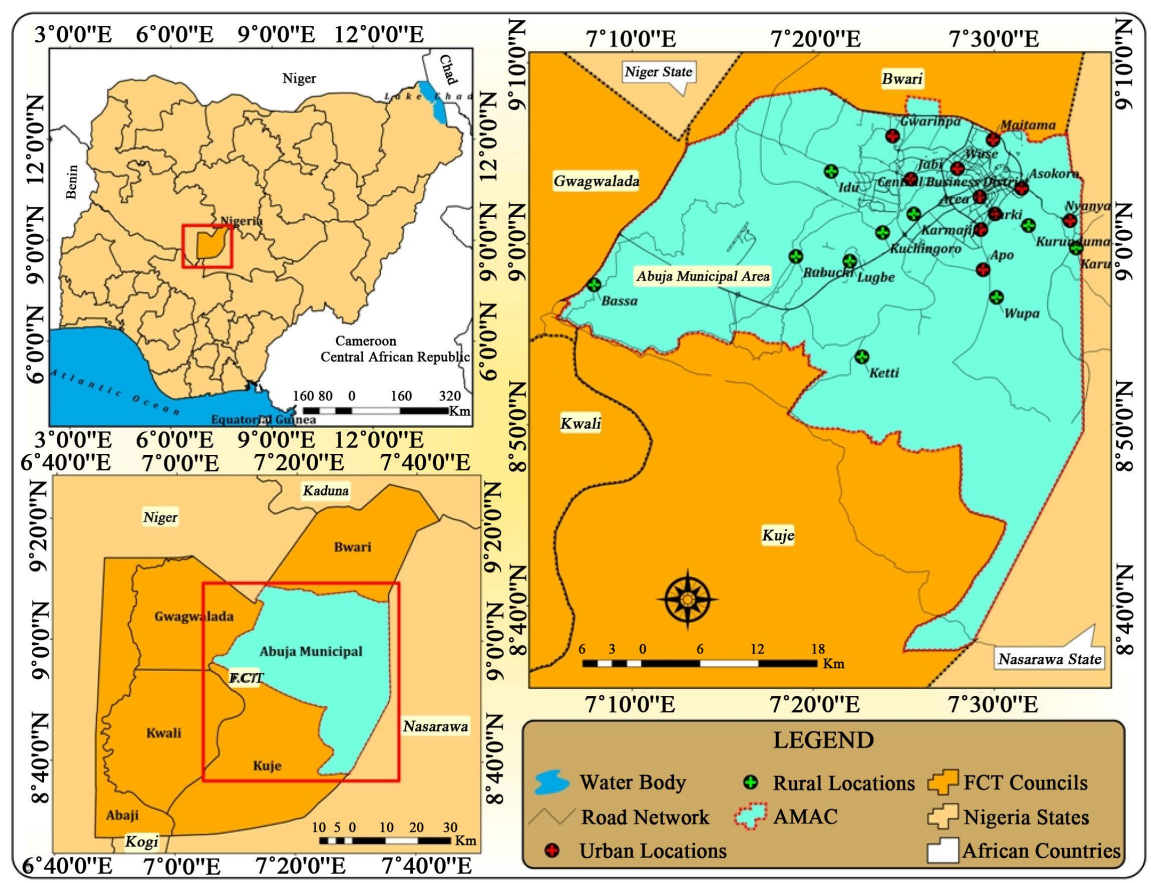

Figure 1. Map of FCT showing AMAC, inset: Map of Nigeria showing FCT.

It records relative humidity in the dry season which goes as high as (20\%) in the afternoons at the northern high elevations and about $(30 \%)$ in the extreme south. During the rainy season, relative humidity rises as much as (50\%) [14].

The FCT falls within the Guinean forest-savanna mosaic zone of the West African sub-region. Patches of rain forest, constituting about $7.4 \%$ of the total vegetation, occur to the Gwagwa plains, towards the rough terrain in the south-east where a landscape of gullies and rough terrain is found [15]. The dominant vegetation of the area is classified into these savannah types, park/grassy savannah, savannah woodland, and shrub savannah, with the grassy savannah the most dominant class. The soil is basically alluvial and luvisols making it a fertile ground for agriculture and vegetation growth. Abuja has witnessed a large influx of people into the city, and this unprecedented increase has led to the emergence of satellite towns and smaller settlements to accommodate this increased populace [12]. This increase in the physical boundaries implies a corresponding loss of vegetation and land in the area thereby a direct impact on the micro-climate.

\subsection{Image and Pre-Processing}

The landsat data were downloaded from USGS Earth Explorer, in 2017. The Thematic Mapper (TM) images were downloaded for $26^{\text {th }}$ Dec., 1986. The Enhance Thematic Mapper plus (ETM+) images was downloaded for $27^{\text {th }}$ Dec., 2001 and the Operational Land Imager (OLI) for $28^{\text {th }}$ Dec., 2016. The intervals of +15 years were deliberately chosen by the researcher to ensure uniformity between the datasets. The landsat satellite data have $30 \mathrm{~m}$ spatial resolutions, the 
TM/ETM+ images have spectral range of $0.45-2.35$ micrometer $(\mu \mathrm{m})$ with bands 1 to 7 and 8 respectively while the Operational Land Imager (OLI) extends to band 12. They were used for image classification and LST extraction. The administrative maps of Nigeria containing states and LGA's were gotten from the National Space Research and Development Agency (NASRDA). It is a projected vector shape file, which was used to specify the boundary of the study area.

\subsection{Retrieval of Land Surface Temperature (LST) from Landsat Images}

The mono-window algorithm method is adopted to retrieve the LST from the imageries selected for this study. The landsat-5 TM thermal bands 6 (10.40 $12.50 \mu \mathrm{m})$, ETM+ bands $6 \mathrm{~L}(10.4-12.5 \mu \mathrm{m})$ and TIRS 10 and $11(10.60-11.19$ $\mu \mathrm{m}$ ) have a spatial resolution of $30 \mathrm{~m}$ respectively which is considered suitable as shown by many literatures for capturing the multifaceted intra-urban temperature differences thus making it effective for urban climate analysis. The landsat ETM+ sensor, images of the thermal band is taken twice: one in the low-gain mode (band 6L) and the other in the high-gain mode (band 6H). Band 6L is used to image surfaces with high brightness, band $6 \mathrm{H}$ is for low brightness. Band $6 \mathrm{~L}$ was used in this study, due to errors contained in the $6 \mathrm{H}$ band. Consequently, the landsat thermal bands were used to retrieve LST over the study area for the three different periods $(1986,2001$, and 2016) using various procedures which range from radiometric calibration, conversion of DN to radiance, correction for atmospheric absorption, re-emission and surface emissivity which has been used in [16] as described below:

Conversion of Digital Numbers (DN) of the Bands to Spectral Radiance

$$
L_{\lambda}=\left\lfloor\frac{L_{M A X}-L_{M I N}}{Q_{\text {Calma }} x-Q_{\text {CALMIN }}}\right\rfloor \times(D N-1)+L_{M I N}
$$

where,

$L_{M A X}=$ the spectral radiance that is scaled to $Q_{C A L M A X}$ in $\mathrm{W} /\left(\mathrm{m}^{2 *} \mathrm{sr}^{\star} \mu \mathrm{m}\right) ; L_{M I N}$ = the spectral radiance that is scaled to $Q_{C A L M I N}$ in $\mathrm{W} /\left(\mathrm{m}^{2}{ }^{*} \mathrm{sr}^{*} \mu \mathrm{m}\right) ; Q_{C A L M A X}=$ the maximum quantized calibrated pixel value (corresponding to $L_{M A X}$ ) in $D N=$ 255; $Q_{C A L M I N}=$ the minimum quantized calibrated pixel value (corresponding to $\left.L_{M I N}\right)$ in $D N=1$.

Conversion from Spectral Radiance to At-Satellite Brightness Temperature [16]

$$
T=\frac{K_{2}}{\operatorname{In}\left(\frac{K_{1}}{L_{\lambda}}+1\right)}-273.15
$$

where, $T=$ At-satellite brightness temperature; $L_{1}=$ Spectral radiance (gotten from equations -and-); $K_{1}=$ Band specific thermal conversion constant from the metadata, $x$ is the thermal band number); $K_{2}=$ Band specific thermal conversion constant from the metadata; $-273.15=$ Constant for conversion from Kelvin to Degrees Celsius as shown in [16]. 


\section{Correcting for Land Surface Emissivity (LSE) [16]}

The temperature values obtained using Equation (2) are reference to a blackbody. Therefore, corrections for spectral emissivity $(\varepsilon)$ became necessary according to the nature of land cover (Equation (3))

$$
e=0.004 P V+0.986
$$

where, $e=$ Land Surface Emissivity; 0.004 and $0.986=$ Constants for emissivity estimation; $P_{V}=$ Proportion of vegetation [16] given by the equation

$$
P_{V}\left(\frac{N D V I-N D V I_{\min }}{N D V I_{\max }-N D V I_{\min }}\right)
$$

where, $N D V I=$ Normalized Differential Vegetation Index as computed with Equation (1) for each of the years; $N D V I_{\min }=$ Minimum value of $N D V I$ for that year; $N D V I_{\max }=$ Maximum value of $N D V I$ for that year [16].

Estimation of the Land Surface Temperature [16]

$$
L S T=\frac{B_{T}}{1+W} \times \frac{B_{T}}{P} \times \operatorname{In}(\Sigma)
$$

where, $L S T=$ Land Surface Temperature; $B_{T}=$ At-satellite brightness temperature; $W=$ Wavelength of emitted radiance $(\mu \mathrm{m})[16]$ given as:

$$
P=h \times \frac{c}{S}\left(1.438 \times 10^{-2} \mathrm{~m} \cdot \mathrm{K}\right)=14380
$$

where, $h=$ Planck's constant $\left(6.626 \times 10^{-34} \mathrm{~J} / \mathrm{s}\right) ; S=$ Boltzmann constant $(1.38 \times$ $\left.10^{-23} \mathrm{~J} / \mathrm{K}\right) ; C=$ Velocity of light $\left(2.998 \times 10^{8} \mathrm{~m} / \mathrm{s}\right) ; \varepsilon=$ LSE.

\subsection{Statistical Analysis}

Pearson's Product Moment Correlation analyses are carried out to determine the relationship between land use/land covers and land surface temperature. The Pearson's Product Moment Correlation Analysis is a statistical method that tests the measures of linear association between two quantitative variables, with the linear association going from +1 to -1 in decreasing order of strength. This equation [17] is given as:

$$
r=\frac{\Sigma X Y-\frac{(\Sigma X)(\Sigma Y)}{N}}{\left(\Sigma X^{2}-\frac{(\Sigma X)^{2}}{N}\right)\left(\Sigma Y^{2}-\frac{(\Sigma Y)^{2}}{N}\right)}
$$

where:

$R=$ Correlation Coefficient;

$X=$ Independent variable, which is the Land use classes in decreasing order of reflective capacity;

$Y=$ Dependent variable, which is the land surface temperature readings associated with each class;

$n=$ Observations 
To test the strength of the correlation, the coefficient of determination was used and given by:

$$
C / D=r^{2}
$$

where $C / D=$ Coefficient of determination;

$$
r^{2}=\text { correlation coefficient. }
$$

\section{Result Presentation and Discussion}

\subsection{Determination of the Relationship between LULC and LST}

Zonal statistics were generated from the classified images (Figure 2 and Figure 3) to determine the relationship between land cover classes and the difference in surface temperatures between 1986 and 2016. The zonal statistics tool provides a summary of simple statistics based on groups. For this analysis, surface temperatures were summarized by the number of class used in this work; Built-up (1), Rock Outcrop (2), Bare surface (3), Vegetation (4), and Water body (5). Output statistics included mean and standard deviation. A correlation analysis was then carried out to determine the strength of the relationships between each class and their corresponding LST value, per interval. The results of these analyses show that a strong relationship exists between the LULC classes and the LST variation in Abuja Municipality (Figures 4-6). It confirms the assertion that

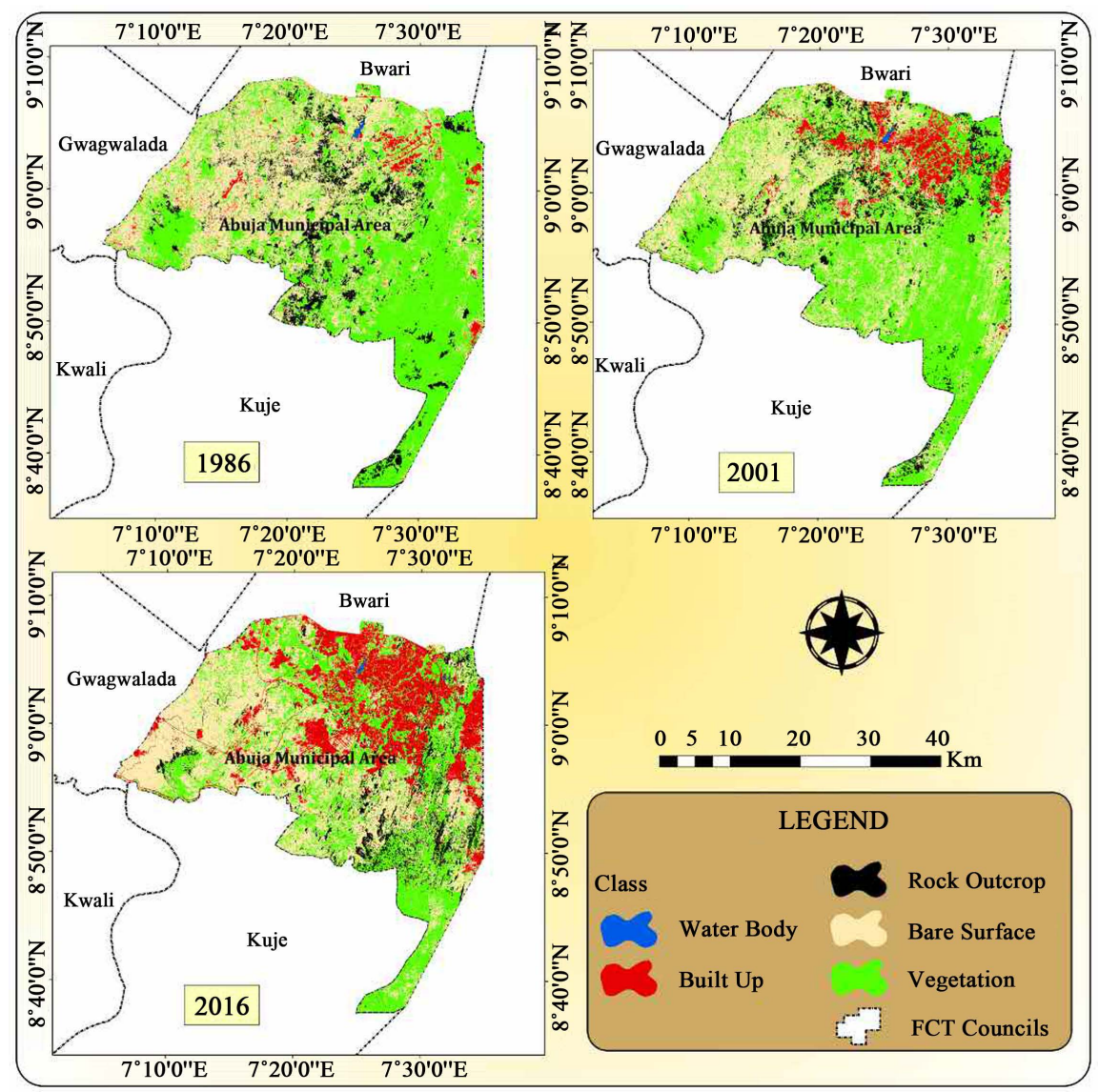

Figure 2. Pictorial view of the entire LULC changes observed between 1986 and 2016. 


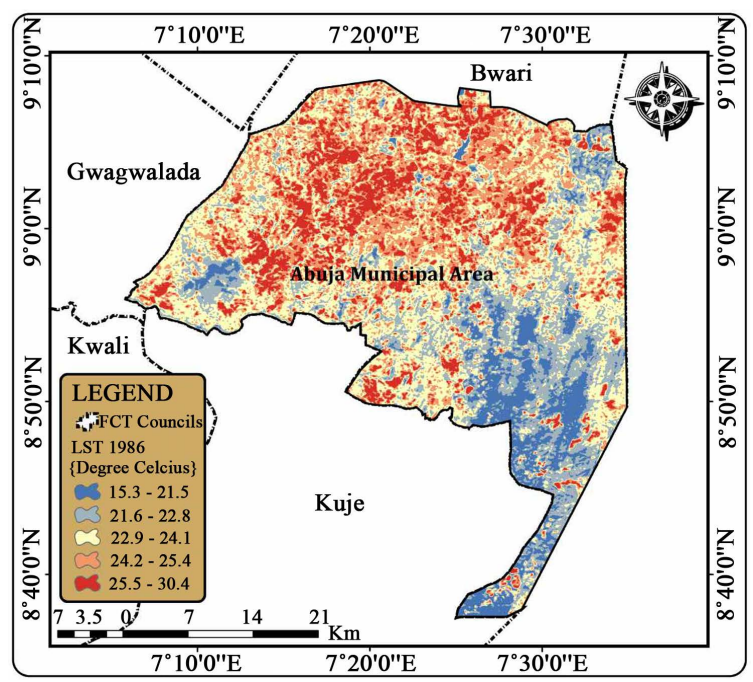

(a)

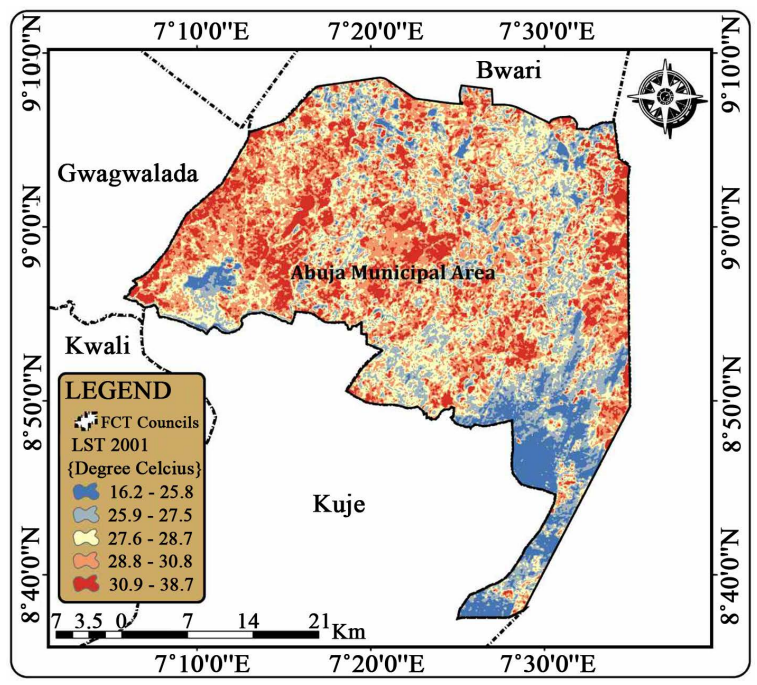

(b)

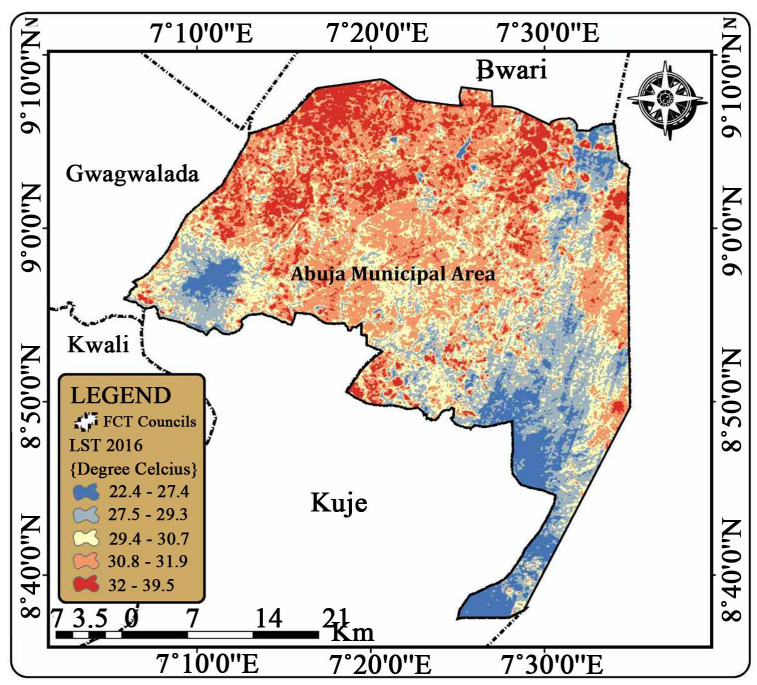

(c)

Figure 3. LST distribution over Abuja based in 1986 (a), 2002 (b) and 2016 (c). 


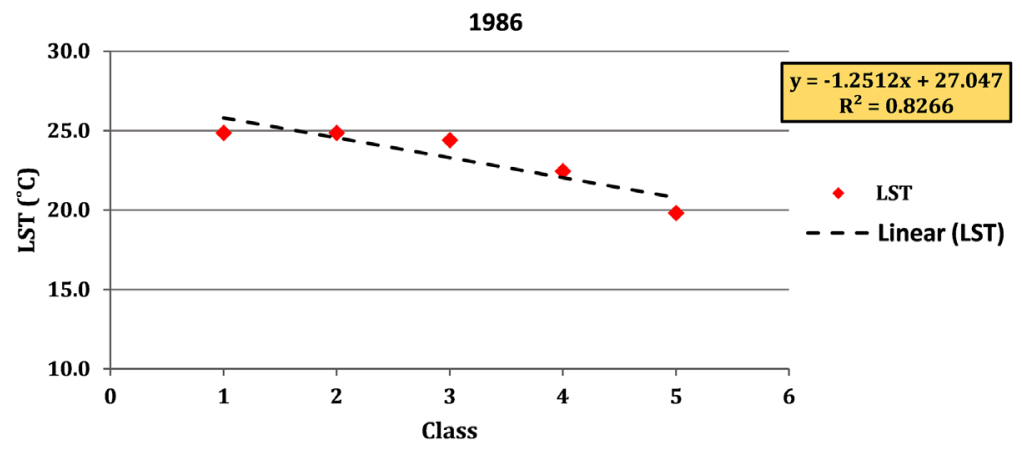

Figure 4. Correlation scatter plot for 1986 LULC and LST.

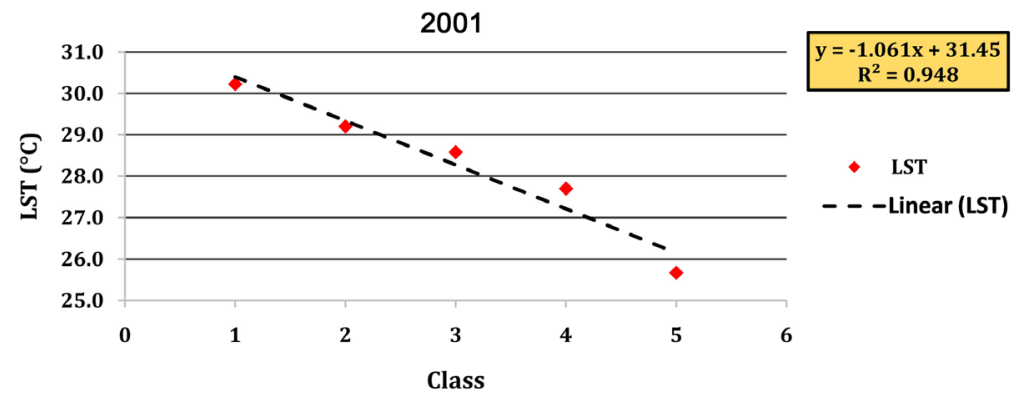

Figure 5. Correlation scatter plot for 2001 LULC and LST.

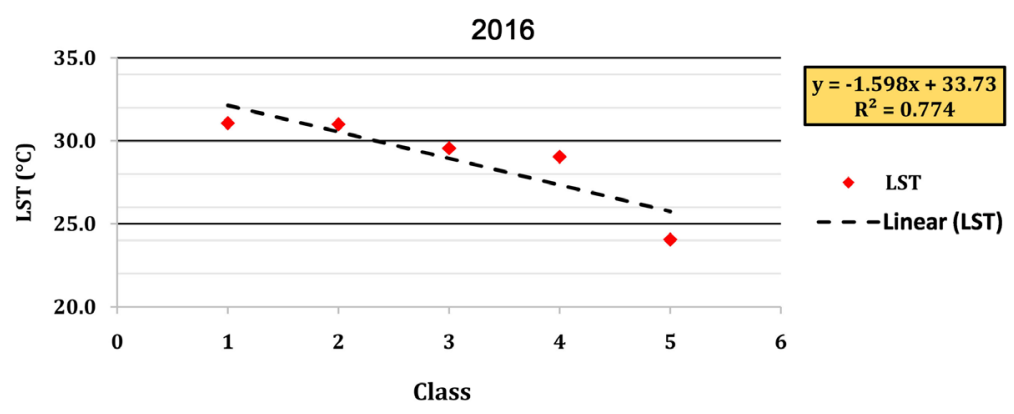

Figure 6. Correlation scatter plot for 2016 LULC and LST.

LULC greatly influences the spatial distribution of land surface temperature [18]. Based on the material composition of each land use class, a higher or lower LST values is expected to occur. Classes with higher absorptivity such as vegetation and water bodies have lower temperatures, while those with low absorptivity and high albedo have higher temperatures (Figures 2-6).

\subsubsection{Correlation Analyses between LULC and LST for 1986}

For 1986, built-up and rock outcrops were associated with the highest temperatures, averaging $24.88^{\circ} \mathrm{C}$, with the water body being the lowest at $19.84^{\circ} \mathrm{C}$ for that year (Figure 4).

The correlation analysis showed a strong coefficient of determination $\left(r^{2}\right)$ of 0.8266 (Figure 4), as a strong linear relationship exists between +0.5 and +1.0 at 95\% level of confidence, which indicates a strong relationship between the LULC classes and their associated LST values for 1986 (Figure 4). This result is in line 
with the findings [19] [20] [21] [22] who revealed that land use and cover greatly affects the land surface temperature of a locality.

\subsubsection{Correlation Analyses between LULC and LST for 2001}

In 2001, a significant increase in surface temperature was observed in each of the classes. The lowest value of the year was higher than the highest value of 1986. Built-up areas increased to $30.22^{\circ} \mathrm{C}$ (almost $6^{\circ} \mathrm{C}$ increase from 1986), while bare surfaces increased to $29.20^{\circ} \mathrm{C}$. Water bodies worryingly increased to $25.67^{\circ} \mathrm{C}$, a consequence of many factors. The correlation analysis showed a strong coefficient of determination $\left(r^{2}\right)$ of 0.9486 (Figure 5), which indicates an even stronger relationship between the LULC classes and their associated LST values for 2001 (Figure 5).

\subsubsection{Correlation Analyses between LULC and LST for 2016}

These values continued to increase to 2016 (Figure 6), with built-up areas attaining an average temperature of $31.07^{\circ} \mathrm{C}$ and increase of $0.84^{\circ} \mathrm{C}$ from 2001. The temperature of the bare surfaces increased by $1.79^{\circ} \mathrm{C}$ to $30.99^{\circ} \mathrm{C}$, and that of the rock outcrops increased to $29.54^{\circ} \mathrm{C}$. The water body temperature reduced to $24.05^{\circ} \mathrm{C}$. The correlation analysis also showed a strong coefficient of determination $\left(r^{2}\right)$ of 0.7746 (Figure 6), which indicates a slightly weaker, but still strong enough relationship between the LULC classes and their associated LST values for 2016. This weakened relationship strength can be attributed to the reduction in temperature observed by the water bodies.

\subsection{Discussion of Findings}

Between 1986 and 2001, Built-up areas increased significantly by $61.76 \mathrm{~km}^{2}$ (4.4\%), obviously due to expansion of residential area coupled with more anthropogenic activities over the region resulting from dynamic population growth that occurred between those years, and completion of development projects that were planned for that period. The class that contributed the most to this positive increase were bare surfaces as they lost about $36 \mathrm{~km}^{2}(-3.36 \%)$ within fifteen years. This drastic reduction was due to the increase in built-up areas. Most of the bare surfaces were replaced by the rapid development that occurred in Abuja by that period. During this period, the mean land surface temperature increased by $4.9^{\circ} \mathrm{C}$ from $23.5^{\circ} \mathrm{C}$ to $28.4^{\circ} \mathrm{C}$, an increase that was due to the increased urbanisation activity that went on during that period. This statement is backed by the results of the zonal statistics and correlation analyses between the LULC classes and the corresponding LST values. Built up areas were associated with average temperatures of $24.88^{\circ} \mathrm{C}$ in 1986 and $30.22^{\circ} \mathrm{C}$ in 2001 , further pointing to the strong relationship between LULC and LST and how surfaces with high albedo and low absorptivity reflect heat and contribute to the UHI development in an area. The $r^{2}$ for 1986 and 2001 were found to be 0.82 and 0.94 respectively, indicating very strong relationships. Abuja Municipal observed an increased temperature over the period due to the increased impervious surfaces, and loss of vegetative cover. 
Between 2001 and 2016, the built-up areas almost tripled in areal extent, increasing by $185.2 \mathrm{~km}^{2}(12.72 \%)$. The major contributor to this massive increase was bare surface again who lost about $88 \mathrm{~km}^{2}$ to built-up areas. This was due to a lot of reasons such as the development of empty lands and farms by the government (for example, in Jahi, a massive estate with quality road networks is being built off a land that was practically bare) and the rapid development that occurred in the Phase 1 and 2 during this period. The ministers of the FCT during this period took up the responsibility for ensuring the Abuja Master Plan were achieved and pursued diligently. This led to the demolition of buildings and communities situated wrongly (especially during El-Rufai's tenure in 2003-2007), and the intense development of the Phases during this period. Also, more ministries were moved from Lagos to Abuja to continue the transfer of capital headquarters, during this period. The planned and modelled city was achieved but almost failed to adequately put measures in place to control the development of the UHI in the Area Council. The analysis of the LST showed that the surface temperature increased on average by $1.8^{\circ} \mathrm{C}$, although lesser than the one observed in the previous years. A major reason for this lesser increase was the implementation of a smart city model in Abuja, which involved the planting of trees along every street in order to develop an immense shading effect to combat the UHI menace. Nevertheless, it took a longer period for the plan to be fully successful.

\section{Conclusion}

This study adopted a correlation analysis in assessing the relationship between LULC and LST in Abuja Municipal, FCT from 1986 to 2016. The correlation analyses proved that the LULC classes were strongly related to LST; with built-up areas being associated with the highest LST values $\left(31^{\circ} \mathrm{C}\right)$, water bodies were associated with the lowest LST $\left(24.5^{\circ} \mathrm{C}\right)$. The coefficient of determination $\left(I^{2}\right)$ for 2016 was 0.77 , being a strong indicator that a strong relationship existed. This means that built-up areas are major drivers of the increase thermal reflectance in Abuja Municipal due to their reflective and absorptive capacity. To promote thermal comfort in Abuja Municipal, urban planning, and control of building patterns tree-planting exercises are some of the recommendations made.

\section{Conflicts of Interest}

The authors declare no conflicts of interest regarding the publication of this paper.

\section{References}

[1] Enete, I.C., Awuh, M.E. and Amawa, S. (2014) Assessment of Health Related Impacts of Urban Heat Island (UHI) in Douala Metropolis, Cameroon. International Journal of Environmental Protection and Policy, 2, 35-40.

[2] Awuh, M.E., Officha, M.C., Okolie, A.O. and Enete, I.C. (2018) Land-Use/Land- 
Cover Dynamics in Calabar Metropolis Using a Combined Approach of Remote Sensing and GIS. Journal of Geographic Information System, 10, 398-414.

[3] Bharath, S., Rajan, K.S. and Ramachandra, T.V. (2013) Land Surface Temperature Responses to Land Use Land Cover Dynamics. Geoinfor Geostat. An Overview, 54, 50-78.

[4] Alecander, P.J. (2004) Local Climate Classification and Dublin's Urban Heat Island. Atmosphere Journals, 5, 755-774.

[5] Jiang, Y., Fu, P. and Weng, Q. (2015) Assessing the Impacts of Urbanization-Associated Land Use/Cover Change on Land Surface Temperature and Surface Moisture: A Case Study in the Midwestern United States. Journal of Remote Sensing 7, 4880-4898.

[6] Awuh, M.E. (2017) Assessment of the Impact of Land-Use/Land Cover Pattern on Urban Heat Island in Calabar metropolis. Unpublished Ph.D. Thesis, Nnamdi Azikiwe University, Awka.

[7] Kaya, S., Karaca, M., Basar, U.G., Seker, D.Z. and Weng, D. (2012) Assessment of Urban Heat Islands Using Remotely Sensed Data. Ekoloji, 21, 107-113.

[8] Weng, Q., Liu, H. and Lu, D. (2007) Assessing the Effects of Land Use and Land Cover Patterns on Thermal Conditions Using Landscape Metrics in City of Indianapolis, United States. Urban Ecosystems, 10, 203-219.

[9] Kalnay, E. and Cai, M. (2003) Impact of Urbanization and Land Use Change on Climate. Nature, 423, 528-531.

[10] Enete, I.C., Awuh, M.E. and Ikekpeazu, F.O. (2014) Assessment of Urban Heat island (UHI) Situation in Douala Metropolis Cameroon. Journal of Geography and Earth Sciences, 2, 35-40.

[11] Gallo, K.P., McNab, A.L., Karl, T.R., Brown, J.F., Tarpley, J.O. and Hood, J.J. (1993) The Use of NOAA AVHRR Data for Assessment of the UHI Effects. Journal of Applied Meteorology, 32, 899-908.

[12] IPA Associates (2010) The Master Plan for Abuja, the New Federal Capital of Nigeria. FCDA, Abuja.

[13] Knoema (2017) Projected Populations in Nigeria. http://www.knoema.com/NGPOP2015/population-of-nigeria-2016?tsId=1002860\#

[14] NIMET (2016) Nigerians Concern Over Increase in Temperature. NOI Polls, Abuja.

[15] Nigeria Online (2013) Abuja Physical Setting. http://www.onlinenigeria.com/abuja

[16] Awuh, M.E., Officha, M.C., Okolie, A.O. and Enete, I.C. (2018) A Remote Sensing Analysis of the Temporal and Spatial Changes of Land Surface Temperature in Calabar Metropolis, Nigeria. Journal of Geographic Information System, 10, 562-572. https://doi.org/10.4236/jgis.2018.105030

[17] Yim, K.H., Nahm, F.S., Han, K.A. and Park, S.Y. (2010) Analysis of Statistical Methods and Errors in the Articles Published in the Korean Journal of Pain. The Korean Journal of Pain, 23, 35-41. https://doi.org/10.3344/kjp.2010.23.1.35

[18] Voogt, J. and Oke, T. (2003) Thermal Remote Sensing of Urban Climates. Remote Sensing of Environment, 86, 370-384. https://doi.org/10.1016/S0034-4257(03)00079-8

[19] Enete, I.C. and Alabi, M.O. (2012) Characteristics of Urban Heat Island in Enugu during Rainy Island Analysis in the City of Rome. Remote Sensing, 45, 1400-1415.

[20] Falahatkar, S., Hosseini, S.M. and Soffianian, A.R. (2011) The Relationship between 
Land Cover Changes and Spatial-Temporal Dynamics of Land Surface Temperature. Indian Journal of Science and Technology, 4, 76-81.

[21] Oluwatola, A. and Abegunde, L. (2015) Impact of Landuse Change on Surface Temperature in Ibadan, Nigeria. International Journal of Environmental, Chemical, Ecological, Geological and Geophysical Engineering, 12, 235-240.

[22] Orhan, O., Ekercin, S. and Dadaser-Celik, F. (2014) Use of Landsat Land Surface Temperature and Vegetation Indices for Monitoring Drought in the Salt Lake Basin Area, Turkey. The Scientific World Journal, 2014, Article ID: 142939.

https://doi.org/10.1155/2014/142939 